\title{
AGRICULTURAL LAND-USE SYSTEMS AND CLIMATE CHANGE AMONG SMALL FARMERS IN NIGERIA
}

\author{
T. G. Apata ${ }^{1}$, G. Y. N'Guessan' ${ }^{2}$ K. Ayantoye ${ }^{3}$ and O. S. Idowu ${ }^{1}$. \\ ${ }^{1}$ Federal University Oye-Ekiti, Nigeria \\ ${ }^{2}$ Jean Lorougnon Guédé University, Côte d'Ivoire \\ ${ }^{3}$ Kwara State University, Nigeria \\ dayo.apata@fuoye.edu.ng
}

\begin{abstract}
In sub-Saharan-Africa (SSA), agriculture land-use supports the livelihoods of the majority of people. Landuse for agricultural-activity is an economic-activity that is highly dependent upon weather and climate that produce food and fibre necessary to sustain human life. Hence, land-use for agriculture is expected to be vulnerable to climate variability. This paper examines this relationship. The paper presents data and generated evidence-based decision making under risk and uncertainty as influenced by climate change and its effects on agricultural land-use/outputs. Farm-level cost-route survey of cross-sectional national-data of 800 respondents was used for analysis. Data were analyzed and presented using the tools of descriptive statistics, trans-logarithms model and multivariate probit model (MVP). The study indicated a strong relationship between efficient use of agricultural-land and adaptive-processes to climate-change. Thus, providing data and analysis that strengthen policy decisions on land-use and climate change. Hence, policies of promoting and motivating sustainable land-use management need to be entrenched.
\end{abstract}

\section{INTRODUCTION}

Literature revealed about $75 \%$ of farming households in sub-Saharan Africa (SSA) obtained livelihood from agricultural land-use (Ali \& Erenstein, 2017, Muthee et al., 2018). In Nigeria, agriculture land-use supports the livelihoods of the majority of people by providing $80 \%$ of employment and outputs from agriculture contributes 43\% to the gross domestic product (GDP) (Apata, 2011; Ohwo, 2015). Land use for agricultural activity is an economic activity that is highly dependent upon weather and climate in order to produce the food and fiber necessary to sustain human life (AGRA, 2017). Hence, land-use for agriculture is expected to be vulnerable to climate variability and change (Dale, 1997). Climate change has been considered to have disastrous effects on human survival (Zahid et al., 2019). It has become a major obstacle to developing economies, like Nigeria (Ayinde et al., 2011; Apata, 2011). Hence, increase in its vulnerabilities would further result in higher susceptibility of the poor and other communities who depend mainly on agriculture except there is an effective intervention. Past studies have argued that some agricultural activities influenced climate vagaries through the creation of anthropogenic Greenhouse gases (GHG) emissions (UNEP, 2016, Shikuku et al., 2017). In Nigeria, these activities include large number of cattle that roams the road indiscriminately and excreta around disturbing the top soils and destroying food crops, unsustainable agricultural land-use, inadequate manure management, improper use of agro-chemicals among others. Among these activities unsustainable agricultural land-use have been dominant and have been argued to have generated at least 52\% of GHG emissions (Field et al., 2014; Muchuru \& Nhamo, 2017). Consequently, the study examined agricultural land-use management and its relationship to climate change. Also, how the people have been coping with the climate change vagaries.

Several studies in Nigeria have examined agricultural land-use and climate change (Ayinde et al., 2011; Audu et al., 2013; Ohwo, 2015; Okpara et al., 2017). Most of these studies were conducted at the Local Government level or at the State level, and these studies are useful because they helped to identify the structure of agricultural land-use management at the local and state levels respectively. However, their application for policy formulation at the national level is limited due to small scope. This study however, uses national data, and will add to the already existing body of knowledge on agriculture and climate change. Agricultural land-use and climate change: Evidence of relationship

Agricultural land-use here refers to all land cover type (e.g., arable, improved grassland, extensive grassland), and management of such land (e.g., cropping patterns, fertilizer inputs, grazing regimes). Other disturbance effects such as erosion and wildfires are a function of both land use and climate. Climate change 
and agricultural land-use interact to impact on biodiversity through a wide range of mechanisms (Barbier \& Hochard, 2016) Understanding these interactions will be necessary to sustain a reliable biodiversity, influencing adaptive capacity that can minimize risks and increase opportunities for the conservation of biodiversity (Mohmmed et al., 2018). A review of the literature dealing with the relationship between agricultural land-use and climate change clearly shows that land-use change has had much greater effects on ecological variables (Maddison, 2007; Chandra \& Venkatachalam, 2013; Abdul-Razak \& Kruse, 2017).

Nyamwanza et al. (2017) study in 12 food-insecure regions of SSA and South Asia reported that climate change significantly impacted agricultural production negatively for past decades and this will continue if no significant interventions are put in place. Chaudhury et al. (2016) deduced that climatic elements are extremely charged, flood and drought are on the increase. Past study argued that deforestation (for agricultural expansion and fuel wood) influenced climate change in the southern part of Nigeria (Apata, 2011). Climate change will also affect land use through various interventions of human activities and policy (FAO, 2017). Abid et al. (2016) argued that agricultural land-use influences about half of the global emissions of two of the most potent non-CO2 GHG: nitrous oxide $\left(\mathrm{N}_{2} \mathrm{O}\right)$ and methane $\left(\mathrm{CH}_{4}\right)$. These noncarbon GHGs have powerful greenhouse effects and have greater longevity than $\mathrm{CO}_{2}$. Belcher et al. (2015) contended that agricultural activities contributes $30-40 \%$ of anthropogenic GHG emissions of which about $75 \%$ happened in developing countries and this share might rise above $80 \%$ by 2050 . FAO (2017) documented that developing countries GHG emissions have witness a significant increase over the years, from 14\% (2011) to 36\% (2017). In Nigeria GHG emission from agriculture accounts for about $80 \%$. As the global population and the demand for food continue to grow, GHG emissions from the land-use for agriculture are expected to increase over time (Wamunyima \& Miga 2014; McDowell et al., 2016).

Climate variations have started to degrade Nigeria's economic growth rates, adversely affecting the livelihood of millions of people. Keeping in mind its importance for the survival of civilizations, it is indispensable for the agriculture institutions, government and the policy makers to address these issues. FAO (Food and Agriculture Organization of the UN) indicated that by 2050 the world will need to double food production in order to feed its growing population. Climate change and its consequences will have a decisive impact on productivity in agriculture. If we fail to successfully manage the process of adapting agriculture to climate change, we will have to expect a sharp decline in food production. Hence, adapting agriculture to climate change is the key to food security in the 21 st century. In order to curtail the threat of climate change, efforts must be channeled to improve on the present sustainability's of land-use for agricultural activities among farmers in SSA countries. Hence, this study examines the land-use for agricultural activities, sources and threat of climate change on agricultural outputs/income. Moreover, this research will provide relationship between agricultural land-use and climate variability, and its influence on climate change and vice-versa. This study will also look at the heterogeneity of land use for agricultural purposes and the influence of climate change, as well as adaptive processes.

\section{METHODOLOGY \\ Area of study}

Nigeria comprises of a geographical area of 923,768 square kilometers with a projected population of around 140 million (2006 estimates) people. Nigeria lies exclusively within the tropics along the Gulf of Guinea on the western coast of Africa. The country has a favorably diversified agro ecological condition, which makes it possible for the production of a wide range of agricultural products. Less than $50 \%$ of the country's cultivable agricultural land is under cultivation. Even then, smallholder and traditional farmers who use rudimentary production techniques, with resultant low yields, cultivate most of these lands. The country is divided into four major agro-ecological zones which is used as a base of analysis for this study.

\section{Method of data collection}

Both primary and secondary data were used. A cross-sectional data from 1200 farmers were collected through farm level rigorous cost route surveys, out of which 880 ( $73.33 \%$ response rate) data found useful. The 320 unused data contained incomplete data, questionnaire lost in transit and data that cannot properly be transcribed. Data were collected with the assistance of pre-tested, structured- 
questionnaire administered by sixteen-trained enumerators. However, the secondary data were obtained from the records of various Agricultural Developments Projects (ADPs), Land records department of various Federal and State Ministries respectively. Data collected include socio-cultural/economic, agronomic, land use data, environmental, prices on input and output data among others.

\section{Sampling Techniques and procedures}

Multi-stage sampling technique was engaged in choosing the sample desirable for this study. Firstly, division of the country into four regions: Core North, North central, Southern part and South-south and from each region two States were selected based on data availability in actualization of the study stated objectives. Secondly, two locations in each state were identified through secondary sources information about the data on heterogeneity of land-use systems and high intensity of farming operations. In addition, poverty status as provided by secondary sources too inspired the choice of these locations. Thirdly, selection of the farmhouseholds from sixteen identified communities/towns, where 55 data were provided from each household to give 220 per region and 880 overall. Data collection were done through a modified form of simple random sampling called the random walk method. Also, field observation and complimentary key informant interviews surveys (KIIS) were held with reputable farmers to validate information. Also, assistance of competent scientists/researchers were sought for in the identification of certain land use system, degradation parameters and indices among others. Our analysis focuses on access to land use and management practices adopted at the household level and interactions with climate change. "Land access" refers to land which is under the household's use rights, so long as it is regularly utilized, including rented land. This generally includes all cropped land, wood lots, fallow land, land under tree crops, gardens and rented land. Climate change interactions were captured through level of perceptions and adaptive processes used by the respondents.

\section{Method of data analysis}

The analytical tools employed in this study are developed to analyze the data in order to fulfill the stated objectives of this study. Therefore a combination of analytical tools including descriptive, statistical and econometric procedures were utilized.

\section{Summary Reports from the sample surveys}

The people were asked whether they noticed changes in their environments; below are their responses: The temperature is higher ( $83 \%$ ); Water evaporation from the ground is so fast $(75 \%)$ Spread of agricultural pests and weeds on crop land (67\%); Violent rain and hailstorms (68\%); Delayed rainfall (65\%); Less clearly defined seasons (rains sometimes arrive a month late or finish early, rains quickly gave way to sun or dry periods during the rainy season) $(62 \%)$. Respondents $(95 \%)$ were convinced that the vagaries of the climate are a sign of divine anger, "as there are many sinners in our midst and God is trying to punish us; like floods with serious consequences".

The costs associated with crops damaging weather events double each decade as the people $(81 \%)$ indicated that their crops were devastated by torrential rains and a series of freak hailstorm. Downpours (Rainfall) were more intense in the past years that always leave a trail of destruction on the farms (78\%). On the other hand lack of water or delayed downpours threatened crop production activities. The adverse effect of this is that many (64\%) have abandoned their crop farming activities due to low outputs to other sectors. Many of the communities/farmers (78\%) do not attribute these changes to climate change but the soil no longer productive. Respondents $(76 \%)$ confirmed these incidences as curses from their ancestors who are unhappy due to lack of appeasement to these gods.

\section{Solutions suggested as documented from the sample surveys.}

Need agricultural insurance (79\%), Weather alert (Radio and Television for daily weather forecast and relevance to agricultural activities) (75\%) to help for effective adaptation. Also, effective Meteorological facilities in keeping adequate records of weather forecast are provided. Need Extension agents to educate more on zero tillage, organic agriculture, and better land management techniques. 


\section{RESULTS}

Main characteristics concerning rural households in the area of study revealed about $66.4 \%$ of the respondents were categorized poor out of which $23.2 \%$ were extremely poor. Moreover, $92 \%$ of those in the category of extremely poor respondents seek their agricultural land ownership structure by rentage, while farmland with titled documents constitute $78.6 \%$ of the non-poor. However, the poor category (39.5\%) households depend mainly on agricultural livelihoods, whereas, for non-poor $26.7 \%$ augment farm income with non-farm income. In contrast, the poorer have less education, higher families, greater dependency (children and old members), and are more attached to communal and family land. Moreover, farminghouseholds with less than 2 ha of agricultural land are poorer $(30.1 \%)$ and on family/communal land for farming purposes. Moreover, analysis of land-use policy and role of government and NGO-intervention policies to improve agricultural production revealed a significant role. Moreover, evidence indicated that government-policy intervention programme on land use for agricultural purposes constitutes $8.8 \%$ but focus more on farmers that uses government land (57.2\%) for farming purposes. Likewise, NGO-local intervention (36.9\%) emphasis more on family/communal land (28.6\%). Whereas, for government and NGO (local and international) intervention $(6.3 \%)$ focuses more on households that owned land with titled documents $(3.0 \%)$. The poor do not believe much in adaptation as $31.3 \%$ perceived that there is Climate Change but do not act. Moreover, many of the poor farmers do not take advantage of the various adaptation methods. Similarly, out of the $61 \%$ of the respondents that perceived there is Climate Change and adapt, $54 \%$ are non-poor. Mixed cropping is the dominant adaptation choices (12.3\%) among the respondents, out of which $74.1 \%$ were non-poor. These findings tend to suggest that the poor do not take advantage of the various adaptation methods available. Hence efforts should be gear towards enlighten the poor farmers on the benefits inherent in adaptation to mitigate the effects of climate change.

Trans-logarithmic specification model revealed the sum of the elasticities of output with respect to the physical inputs and the indigenous status that generates an estimated scale elasticity, hence, this indicates the presence of short-run decreasing return to scale (SRD). Interaction between land use variable and management variable generated a coefficient of joint action index of 0.417 , which is statistically significant at $\alpha=0.05$ and is positively related to output level. This result indicated that management employed on land use influenced farm output. Distribution of farms based on FSM indicates that $46 \%$ (mean values $=0.458$ ) of the farmers adopted land use and management practices that reduced land quality. Hence, $54 \%$ of them adopted practices that improved land quality. Farm specific index of short-run sustainability (SRSI) is a product of indices of farm specific inefficiency index (SII) and farm specific index of sustainable land use and management (FSM). SRSI revealed that $69 \%$ of the farmers made unsustainable use of agricultural land coupled with practices of resource-use inefficiency. Although, $31 \%$ of the farmers improved their land productively as indicated by the net balance of the resource-use inefficiency and agricultural land and management practices consequence. Hence, only $31 \%$ of the farmers undertook sustainable production process. Further analysis clearly shown that majority $(76 \%)$ of the non-poor practices sustainable production processes Trend of the relationship revealed the $r=0.207$, that is the Null hypothesis of no correlation amid the two indices in the farms was consented at $\alpha=0.05$ level.

Farmers' perception of long-term temperature, rainfall and precipitation changes indicated that $39 \%$ perceive that adopting mixed cropping can influences reduction on the effects of climate change. Moreover, Low rainfall $(13 \%)$ is the dominant ecological problems farmers faced in the study area. Mixed cropping is the dominant method of adaptive processes. Farmers that have access to information on climate, extension services, and local agro-ecology fare better. Household size, farm and non-farm incomes, and agroecological locales are variables influencing the consciousness of farmers adapt to climate change. Studies specified that educated farmers have a higher probability of perceiving climate change. Access to information on climate change through extension agents or other sources creates awareness and favorable condition for adoption of farming practices that can adapt to climate change.

\section{CONCLUSIONS}


The theoretical basis of this study focused on defining the level and strength of agricultural land use and management and climate change and relationship in between. The study revealed that agricultural land use and management practices induces climate change which in turn influences economic (poverty) status of farmers. Results indicated that farm level analysis of land use and management raised doubt as to how sustainable the system could be considering the signs and magnitudes of the estimated indices. A perspective analysis was carried out on how certain agricultural land-use and management practices could improve land resource use efficiency through effective adaptive processes. Although the poor do not believe much in adaptive measures, while the non-poor tend to take this advantage. Hence efforts should be gear towards enlighten the poor farmers on the benefits inherent in adaptation to mitigate the effects of climate change.

MVP model was used as adaptation factors determinants and was tested for its appropriateness which gave robust estimations. The estimated correlation coefficients among the various adaptation options are significant for 10 out of 19 combinations. Though, results indicated that many of the explanatory variables affected the probability of adaptation as expected, except age and temperature. While age and temperatures are negatively related. Access to information on climate change from extension or other public, sources, farmer-to-farmer extension and knowledge on agro-ecology strengthen the likelihood of climate change perception. This play an important role in the availability and flow of information. Sustainable and positive SRSI, education, extension access and access to agro-ecology information were found to promote adaptation. This implies that education to improve awareness of potential benefits of adaptation is an important policy measure. Hence, the paper suggest that government policies and investments must promote these determinants in order to enhance the adaptive capacity of the rural farmers. Hence, essential to restructure the current intervention programme on climate by embracing climate specific response measures, e.g., distribution of high yielding and tolerant seeds, inculcating good agricultural practices (GAP) and improving on the level of responsiveness among the farmers regarding climatic risks so that farmers can lessen against an expansive range of risk and shocks.

Moreover, policy should focus more on effective and reliable access to information such as mass media and extension on locale-specific climate change and adaptation processes such as mixed cropping and mixed farming. In this regards government policy should provide necessary machineries that will facilitate timely response. In addition, empowerment is crucial in enhancing farmers' awareness. This is vital for adaptation decision making and planning. Combining access to extension and modest income ensures that farmers have the information for decision making and the means to take up relevant adaptation measures. Moreover, encouraging informal social networks and importing adaptive technologies from other SSA countries with similar socio-economic and environmental settings could enhance the adaptive capacity of Nigerian farmers. The study indicated a strong relationship existed between efficient use of agricultural land-use and adaptive processes to climate change. Hence, policies of promoting and motivating sustainable land-use management for better and positive SRSI need to be implemented and providing efficient climatic intervention that will improve on adaptive processes of farmers.

\section{REFERENCES}

Abdul-Razak, M., \& Kruse, S. (2017). The adaptive capacity of smallholder farmers to climate change in the Northern Region of Ghana. Climate Risk Management, 17, 104-122.

Chaudhury, A. S., Ventresca, M. J., Thornton, T. F., Helfgott, A., Sova, C., Baral, P., Rasheed, T., \& Ligthart, J. (2016). Emerging meta-organizations and adaptation to global climate change: Evidence from implementing adaptation in Nepal, Pakistan and Ghana. Global Environmental Change, 38, 1-40.

Abid, M., Schneider, U. A., \& Scheffran, J. (2016). Adaptation to climate change and its impacts on food productivity and crop income: perspectives of farmers in rural Pakistan. Journal of Rural Studies, 47, 254-266.

AGRA. (2017). Africa agriculture status report: The business of smallholder agriculture in Sub-Saharan Africa (Issue 5). Nairobi, Kenya.

Ali, A., \& Erenstein, O. (2017). Assessing farmer use of climate change adaptation practices and impacts on food security and poverty in Pakistan. Climate Risk Management, 16, 183-194. 
Apata, T. G. (2011). Factors influencing the perception and choice of adaptation measures to climate change among farmers in Nigeria. Evidence from farming households in Southwest Nigeria. Environmental Economics, 2(4), 74-83.

Audu, E. B., Audu, H. O., Binbol, N. L., \& Gana, J. N. (2013). Climate change and its implication on agriculture in Nigeria. Abuja Journal of Geography and Development, 3(2), 24-36.

Ayinde, O., Muchie M., \& Olatunji, B. (2011). Effect of climate change on agricultural productivity in Nigeria: A co-integration model approach. Journal of Human Ecology, 35(3), 189-194.

Barbier, E. B., \& Hochard, J. P. (2016). Does land degradation increase poverty in developing countries? PLoS One, 11(5), e0152973.

Belcher, B., Achdiawan, R., \& Dewi, S. (2015). Forest-based livelihood strategies conditioned by market remoteness and forest proximity in Jharkhand, India. World Development, 66, 269-279.

Chandra S. B., \& Venkatachalam, L. (2013). Determinants of farm-level adaptation practices to climate extremes: A case study from Odisha, India. Gujarat Institute of Development Research Gota, Working Paper No. 219, India.

Dale, V. H. (1997). The relationship between land-use change and climate change. Ecological Applications, 7(3), 753-769.

FAO. (2017). The future of food and agriculture: Trends and Challenges. Annual Report.

Field, C. B., Barros, V. R., Mastrandrea, M. D., Mach, K. J., Abdrabo, M. K., Adger, N., ..., \& Burkett, V. R. (2014). In Climate change 2014: impacts, adaptation, and vulnerability. Part A: global and sectoral aspects. Contribution of Working Group II to the Fifth Assessment Report of the Intergovernmental Panel on Climate Change (pp. 1-32). Cambridge University Press.

Muthee, K. W., Mbow, C., Macharia, G. M., \& Leal-Filho, W. (2018). Ecosystem services in adaptation projects in West Africa, International Journal of Climate Change Strategies and Management, 10(4), 533-550.

Maddison, D. (2007). The perception of and adaptation to climate change in Africa. The World Bank.

McDowell, G., Ford, J., \& Jones, J. (2016). Community-level climate change vulnerability research: trends, progress, and future directions. Environmental Research Letters, 11(3).

Mohmmed, A., Li, J., Elaru, J., Elbashier, M., Keesstra, S., Artemi, C., Martin, K., Reuben, M., \& Teffera, Z. (2018). Assessing drought vulnerability and adaptation among farmers in Gadaref region, Eastern Sudan. Land Use Policy, 70, 402-413.

Muchuru, S., \& Nhamo, G. (2017). Climate change and the African livestock sector: emerging adaptation measures from UNFCCC national communications, International Journal of Climate Change Strategies and Management, 9(2), 241-260.

Nyamwanza, A.M., New, M. G., Fujisawa, M., Johnston, P., \& Hajat, A. (2017). Contributions of decadal climate information in agricultural and food systems in east and southern Africa. Climatic Change 143(1-2), 115-28.

Ohwo, O. (2015). Public perception of climate change in Yenagoa, Bayelsa State, Nigeria. Geography Journal, 2015.

Okpara, U. T., Stringer, L. C., \& Dougill, A. J. (2017). Using a novel climate-water conflict vulnerability index to capture double exposures in Lake Chad. Regional Environmental Change, 17(2), 351-366.

Shikuku, K. M., Winowiecki, L., Twyman, J., Eitzinger, A., Perez, J. G., Mwongera, C., \& Läderach, P. (2017). Smallholder farmers' attitudes and determinants of adaptation to climate risks in East Africa. Climate Risk Management, 16, 234-245.

UNEP. (2016). The Adaptation Finance Gap Report 2016.

Wamunyima, M., \& Miga, W. (2014). Assessment of adaptation financial flows in Zambia. Consultancy report prepared for AFAI in Zambia, Unpublished Research.

Zahid, K. B., Ali, G., Sabir, S., \& Fayaz, M. (2019). Relationship between climate and year to year variability in crop yield: Selected districts of Pakistan. Sarhad Journal of Agriculture, 35(1). 